\title{
Análise das patentes de tecnologias relacionadas aos probióticos, prebióticos e simbióticos no Brasil
}

\author{
Analysis of technology patents related to probiotics, prebiotics and symbiotic in Brazil
}

Autores | Authors

Ferlando Lima SANTOS

Universidade Federal do Recôncavo da Bahia (UFRB)

Centro de Ciências da Saúde Santo Antônio de Jesus/BA - Brasil e-mail: ferlandolima@yahoo.com.br

Mariza Alves FERREIRA

Universidade Federal do Recôncavo da Bahia (UFRB)

Centro de Ciências Agrárias, Ambientais e Biológicas

Cruz das Almas/BA - Brasil e-mail:marizaalfer@gmail.com

■ Edilson Araújo PIRES

Universidade Federal do Recôncavo da Bahia (UFRB)

Pró-Reitoria de Pesquisa e Pós-Graduação Rua Rui Barbosa, 710, Centro CEP: 44380-000

Cruz das Almas/BA - Brasil e-mail: edilsonprppg@gmail.com

Fábio Santos de OLIVEIRA Camilla Fernanda Godinho da

SILVA

Universidade Federal do Recôncavo da Bahia (UFRB)

Centro de Ciências da Saúde

Santo Antônio de Jesus/BA - Brasil e-mail:fabioso@ufrb.edu.br camillagodinho@gmail.com

Rafael Bittencourt VIEIRA

Universidade Federal do Recôncavo da Bahia (UFRB)

Centro de Ciências Agrárias, Ambientais e Biológicas

Cruz das Almas/BA - Brasil e-mail: rafabvieira@yahoo.com.br

Autor Correspondente / Corresponding Author

Recebido: Maio 13, 2014 Aprovado: Nov. 12, 2014

\section{Resumo}

Este trabalho avaliou os documentos de patentes depositados no Brasil que fazem referência aos termos probióticos, prebióticos e simbióticos. Os dados foram selecionados nas bases de dados do Instituto Nacional de Propriedade Industrial e do European Patent Office. O ano de 2010 apresentou maior número de patentes depositadas. As indústrias de alimentos e farmacêuticas formam os setores de maior destaque, representando juntas 70\% dos depósitos de patentes nesse ramo. Entre as patentes do setor alimentício, 77,55\% dos depósitos foram efetuados por empresas, recebendo destaque a Nestlé S.A. A busca através dos termos relacionados revela que o Brasil tem um universo de 101 pedidos de proteção de patentes no Instituto Nacional de Propriedade Industrial e que desse total apenas $22,45 \%$ foram oriundos de depositantes do próprio país, implicando na necessidade de ampliar o incentivo à proteção das propriedades industriais para geração de novos produtos.

Palavras-chave: INPI; Alimentos; Lactobacillos spp.; Inovação; Mapeamento.

\section{Summary}

This study evaluated the patent documents filed in Brazil that reference to probiotics, prebiotics and synbiotics terms. The data were selected from the databases of the National Institute of Industrial Property of Brazil and the European Patent Office. The year 2010 had the highest number of patents. The food industries and pharmaceutical sectors form the most prominent, together representing $70 \%$ of patent applications in this field. Among the patents in the food sector, $77.55 \%$ of the deposits were made by companies getting highlighted Nestlé SA A search through the related terms reveals that Brazil has a population of 101 applications for patent protection in the National Institute of Industrial Property and of this total only $22.45 \%$ were derived from depositors own, implying the need to expand the incentive to protection of industrial property to generate new products.

Key words: INPI; Food; Lactobacillos spp.; Innovation; Mapping. 


\section{Introdução}

A Organização Mundial da Saúde define probióticos como [...] micro-organismos vivos que, quando administrados em quantidades adequadas, conferem benefícios à saúde do hospedeiro. (FAO e WHO, 2006). Os prebióticos são ingredientes não digeríveis que afetam beneficamente o hospedeiro pelo estímulo seletivo do crescimento e/ou atividade de uma ou de um número limitado de bactérias no cólon. Já os simbióticos são combinações de prebióticos e probióticos, de forma que um produto simbiótico exerce um efeito tanto prebiótico como probiótico (AGNS e FAO, 2007).

Os produtos lácteos são a forma mais popular de consumo de probióticos e vários novos produtos estão sendo introduzidos nesse mercado. Carvalho et al. (2010), por exemplo, relatam os benefícios desses produtos na saúde do intestino, estando assim associados ao combate a diversas doenças.

A indústria de laticínios tem acrescentado culturas probióticas para conferir propriedades funcionais aos seus produtos. Lactobacilos e bifidobactérias, pertencentes ao grupo de bactérias benéficas, estão sendo utilizados como probióticos para a recuperação e também para a manutenção do equilíbrio da microbiota intestinal (FERREIRA, 2012).

Dados do American Dietetic Association - ADA (2009) revelaram que mais de $80 \%$ dos americanos consomem ou gostariam de consumir os alimentos e/ou bebidas funcionais. Em 2005 o mercado mundial destes alimentos movimentou 73,5 bilhões de dólares, contando com um potencial de crescimento anual de 10\%. Na América Latina o mercado de iogurtes probióticos cresceu $32 \%$ de 2005 a 2007. Embora esses dados não sejam de anos recentes, demonstram que o mercado de alimentos apresenta boas taxas de crescimento, mas o mercado de iogurtes probióticos é ainda mais promissor com taxas de crescimento ainda maiores. No Brasil, não há estimativas precisas sobre o mercado desses produtos, contudo é conhecido que o consumidor norte-americano investe anualmente 90 dólares em alimentos e bebidas funcionais (SAAD et al., 2011).

Pesquisas realizadas pelo North American Probiotics Marckets for Human Nutrition revelam que um total de 698 milhões de doláres foi arrecadado pelo setor de pré e probióticos em 2006, com previsão de 1,70 bilhão de doláres para 2013, sendo o setor das bebidas probióticas o de maior crescimento com taxa de crescimento anual de 24,6\% (SAAD et al., 2011).

Aguirre-Bastos e Gupta (2009) relatam que a facilidade no acesso, uso e análise de informações sobre publicações científicas e patentes deu início a uma forma inovadora de estudar a estrutura e a evolução da ciência. Segundo os autores, nos países da América Latina, por exemplo, há uma grande carência de pesquisadores atuando no setor industrial, o que indica a necessidade de maiores investimentos na formação de pessoas voltadas à produção tecnológica de forma articulada com as demandas para o desenvolvimento dessas nações. Mapeamentos tecnológicos são ferramentas estratégicas que servem para subsidiar políticas de desenvolvimento científico e tecnológico.

O presente estudo avaliou documentos de patentes depositados no Brasil que fazem referência aos termos probióticos, prebióticos e simbióticos, através de um mapeamento tecnológico do banco de dados do Instituto Nacional de Propriedade Industrial (INPI).

\section{Material e métodos}

Foram consultadas em janeiro de 2013 bases de dados de patentes disponíveis na internet, nas páginas do Instituto Nacional de Propriedade Industrial (INPI) que abrange os pedidos de patentes depositados no Brasil e do escritório europeu European Patent Office (EPO) - Espacenet, que abrange patentes depositadas e publicadas em mais de 90 países, incluindo o Brasil, disponível gratuitamente (www.espacenet.com).

O escopo metodológico da pesquisa foi composto das seguintes palavras-chave (sem utilização de acento gráfico) no INPI: probiotic, probiotics; probiotico, probioticos; prebiotic, prebiotics; prebiotico, prebioticos; symbiotic, symbiotics; simbiotico, simbioticos. Os mesmos termos foram utilizados na base de dados do Espacenet, substituindo-se as vírgulas por conectivos entre os termos relacionados. De forma análoga, foram empregados os mesmos descritores para o levantamento sobre a produção científica indexada no mundo entre 1980 e 2011, empregando as bases de dados ISI Web of Knowledge, Scopus e Medline.

A metodologia empregada neste estudo se baseou na coleta de informações a partir dos títulos e resumos dos documentos de patentes encontrados, onde foram selecionados todos os documentos que faziam referência à tecnologia protegida (produtos e processos), bem como tecnologias correlatas (dispositivos).

Para interpretar as informações de interesse, cada documento foi analisado individualmente a partir da identificação do número de patentes encontradas em cada base e deles coletadas as informações relevantes que descrevem as invenções, sendo categorizado de acordo com o tipo de depositante, o país e o setor a que se aplica a invenção. Também se verificou a evolução anual dos depósitos de patentes e das publicações científicas.

\section{Resultados e discussão}

Foram encontradas 107 patentes depositadas no INPI, sendo selecionados 101 depósitos para posterior verificação. A seleção foi realizada por meio de filtros 
aplicados às planilhas no programa Microsoft Excel, eliminando-se os documentos duplicados. A busca pelos termos relacionados aos probióticos, prebióticos e simbióticos no Espacenet contabilizaram 3.036 patentes, o que permite inferir que os depósitos de patentes no Brasil contribuem com 3,33\% deste total. Esses dados podem ser visualizados na Tabela 1.

Filtrando os documentos repetidos, restaram 101 patentes depositadas entre os anos de 1980 e 2011. Porém, entre 1980 e 1998, foram computados apenas quatro depósitos de patentes. A partir do ano 2000 (Figura 1), houve um crescimento do número de patentes depositadas, que se intensificou nos anos entre 2006 e 2010. O ápice dos depósitos ocorreu no ano de 2010, com 29 pedidos realizados junto ao INPI. Ressalta-se que o número de patentes para o ano de 2011 não corresponde ao total desse ano, tendo em vista que a Lei de Propriedade Industrial garante ao depositante 18 meses de sigilo do documento de patentes (BRASIL, 1996).

Os dados obtidos sobre a produção científica no mundo relacionando os termos probióticos, prebióticos, simbióticos entre 1980 e 2010 encontram-se ilustrados na Figura 2, onde pode ser observado que entre os

Tabela 1. Número de depósitos de patentes encontradas no INPI e no Espacenet através da busca dos termos de referência em probióticos, prebióticos, simbióticos.

\begin{tabular}{ccc}
\hline Termos e correlatos & INPI & Espacenet \\
\hline Probiótico & 83 & 2582 \\
Prebiótico & 15 & 94 \\
Simbiótico & 9 & 360 \\
\hline
\end{tabular}

anos de 1980 e 1997 houve um total de 258 publicações registradas, tendo em vista um período de quase duas décadas esta quantidade é considerada baixa quando comparada aos anos subsequentes, atingindo 1.187 publicações em 2010.

A partir dos dados ilustrados nas Figuras 1 e 2 é possível realizar uma avaliação conjunta preliminar sobre a evolução da produção científica e tecnológica envolvendo os termos pesquisados. Nesse sentido, verifica-se que as taxas de crescimento anual, tanto no número de patentes depositadas no INPI quanto no número de publicações cientificas, tornaram-se mais expressivas no final da década de 1990. Esse resultado reforça a existência de uma relação entre produção científica e tecnológica quanto aos produtos pesquisados, sugerindo que grande parte dos produtos patenteados são resultados de pesquisas científicas publicadas.

No Brasil, as pesquisas, em sua grande maioria, são realizadas nas Instituições de Ciência e Tecnologia (ICT). A Lei de Inovação foi regulamentada para mudar esse quadro, aproximando os pesquisadores do setor produtivo a fim de que as empresas alcancem também esse patamar de excelência tecnológica. Diante desse quadro, nos últimos anos, gradativamente, são assinados acordos de cooperações tecnológicas entre as ICT e os setores produtivos, objetivando a transferência de tecnologias para ampliação de suas capacidades tecnológicas e agregação de valores, aumentando a produção científica e tecnológica e ampliando cada vez mais as parcerias entre pesquisadores e indústrias (SANTOS, 2014).

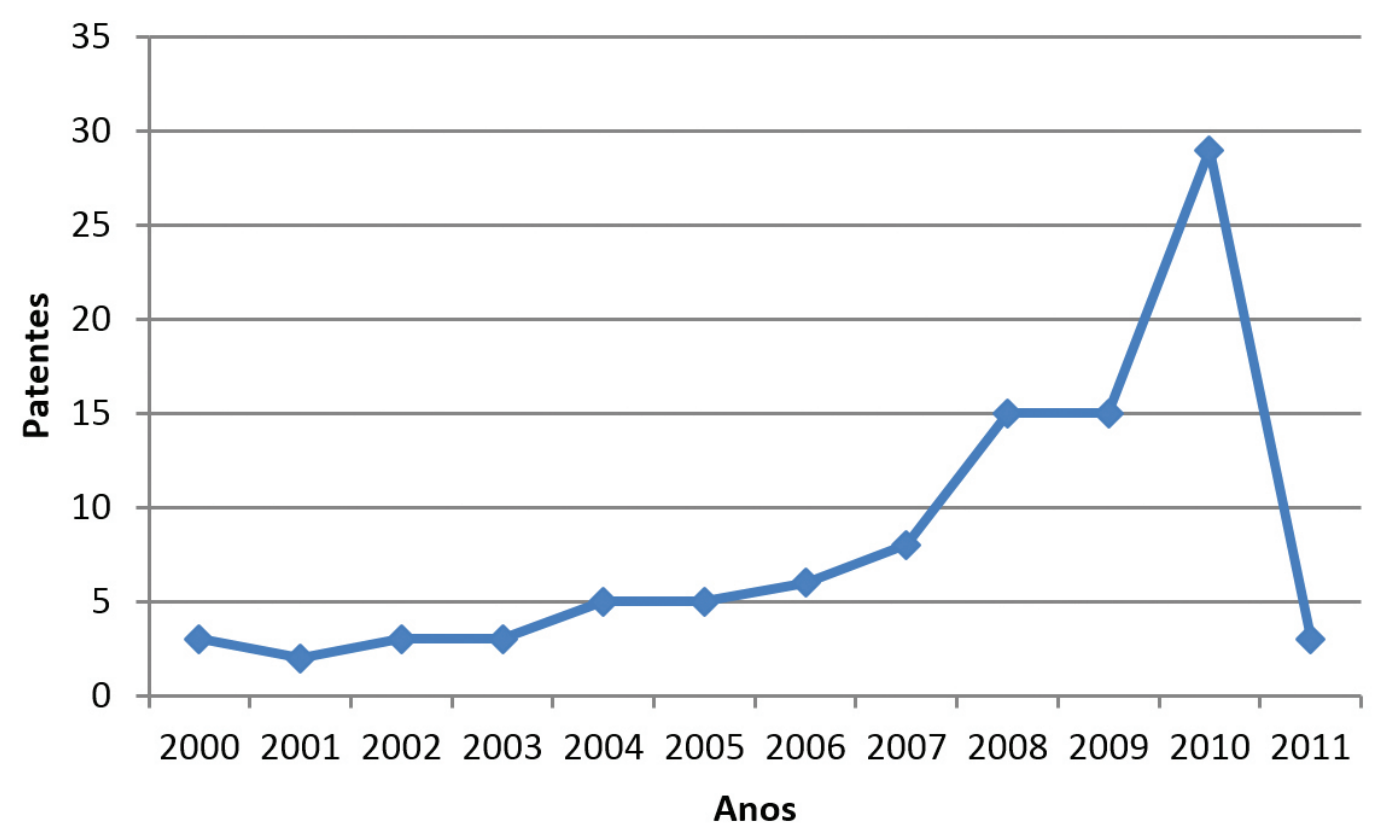

Figura 1. Evolução anual de depósitos de patentes no INPI sobre probióticos, prebióticos, simbióticos entre 1980 e 2011. 
Análise das patentes de tecnologias relacionadas aos probióticos, prebióticos e simbióticos no Brasil

SANTOS, F. L. et al.

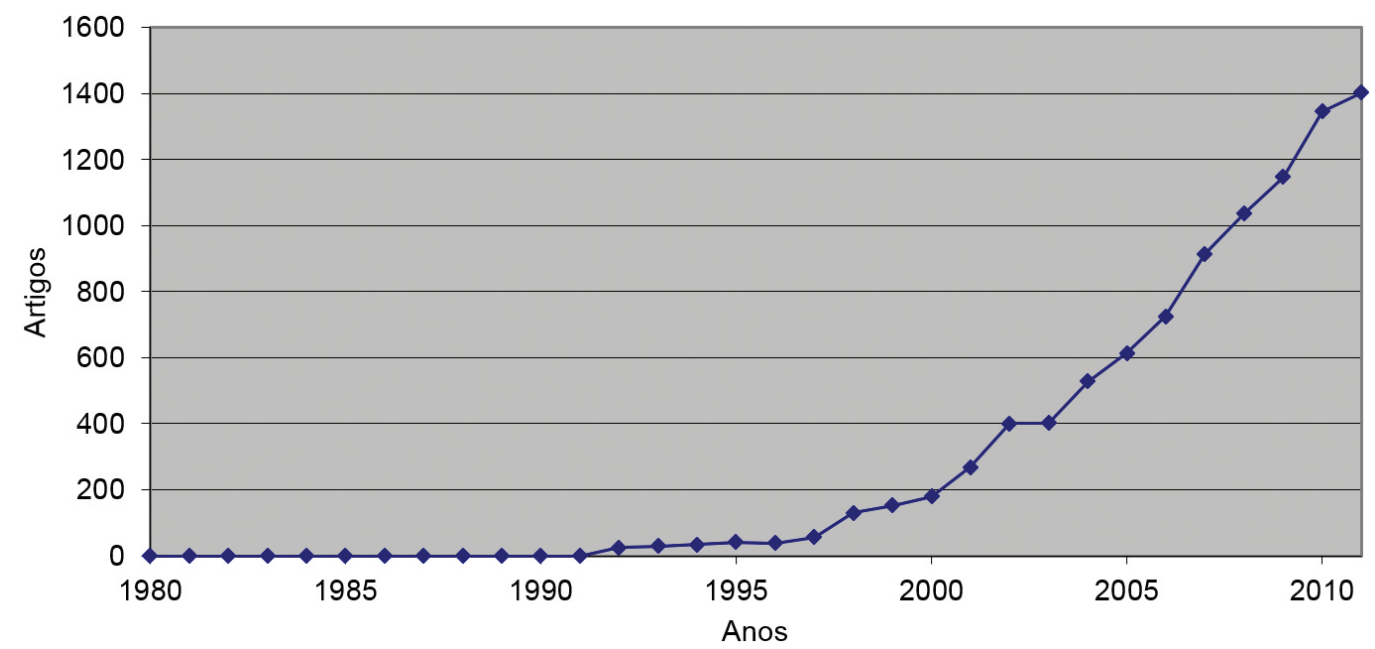

Figura 2. Evolução anual da produção científica mundial indexada nas bases de dados Web of Knowledge, Scopus e Medline entre 1980 e 2011.

A internacionalização da ciência é uma conquista política importante, mas é necessário promover alianças estratégicas internacionais visando aumentar a cooperação interinstitucional para beneficiar os países da América Latina, por exemplo, onde há uma grande carência de pesquisadores atuando no setor industrial, gerando incompatibilidade entre o número de profissionais qualificados e os que realmente atuam no mercado (AGUIRRE-BASTOS e GUPTA, 2009).

No que se refere ao mercado de alimentos funcionais, informações da Euromonitor International (2013) indicam que esse segmento movimentou cerca de US\$ 264 bilhões em 2013. Segundo a organização, a América Latina representa 17\% do mercado de alimentos e bebidas funcionais, movimentando valor próximo a US\$ 45 bilhões, sendo que o Brasil é responsável por US\$ 14,6 bilhões desse total, liderando a tendência de crescimento latino americano nesse setor.

A análise da Figura 3 permite verificar que o setor com maior quantidade de depósitos de patentes no Brasil foi a indústria de alimentos (48\%), seguida do setor farmacêutico, que deteve $22 \%$ das patentes avaliadas.

A preferência dos consumidores de alimentos por produtos com potencial de fortalecer o organismo, prevenir e combater doenças, ao mesmo tempo, com diferentes propriedade funcionais (SOUSA et al., 2013), contribuiu para o crescimento da indústria de alimentos funcionais. Em corroboração, Sousa et al. (2013) ressaltam que $\mathrm{o}$ interesse dos consumidores nesses produtos também está relacionado aos beneficios que estes podem causar à saúde. Pesquisas realizadas com os probióticos revelam eficácia na prevenção de diversos danos à saúde despertando interesse do setor farmacêutico para essas substâncias (SHINOTSUKA et al., 2008).

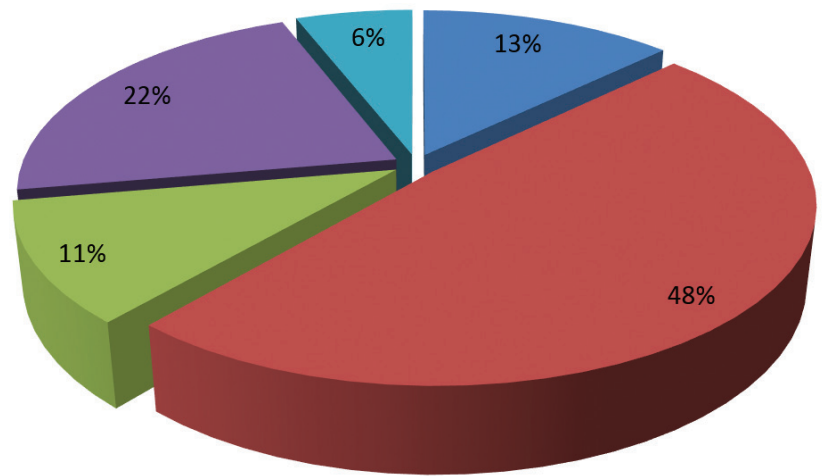

Veterinário Alimentício Outros Farmaceutico Cosmético

Figura 3. Distribuição de depósitos dos documentos de patentes relacionadas aos pró, pré e simbióticos e tecnologias dessa mesma natureza, no Brasil, por setor de aplicação.

Entre as patentes do setor alimentício, 77,55\% dos depósitos foram efetuados por empresas, como observadas na Figura 4. As ICT brasileiras, constituídas majoritariamente por universidades, contribuíram em um percentual de $16,33 \%$ do total analisado, entre elas: a Universidade de São Paulo (USP) com três depósitos; a Universidade Estadual de Campinas (Unicamp) com dois depósitos e a Universidade Federal de Viçosa (UFV), que contabilizou um depósito junto ao INPI.

Segundo Cavalcanti et al. (2001), a Organização para a Cooperação e Desenvolvimento Econômico (OCDE) demonstra que mais de $55 \%$ da riqueza mundial é gerada a partir do conhecimento e dos denominados bens ou produtos intangíveis, como softwares, royalties, serviços de consultoria e bens culturais. Atualmente existe um modelo de gestão, onde gerar conhecimentos, inovar e empreender são condicionantes para a eficiência 
Análise das patentes de tecnologias relacionadas aos probióticos, prebióticos e simbióticos no Brasil

SANTOS, F. L. et al.

na produção. Os autores argumentam que o regime do século XXI contrapõe a antiga sociedade industrial, constatando que o conhecimento é, hoje, a matéria-prima de maior impacto econômico.

Entre as empresas depositantes de patentes dos produtos em estudo, no que se refere à indústria de alimentos houve uma expressiva quantidade de patentes da empresa Nestlé S.A., com um total de 27 depósitos, o que representa aproximadamente $73 \%$ do total dos documentos analisados, conforme pode ser acompanhado na Figura 5.

A Nestlé é uma empresa suíça, sendo a maior produtora de alimentos no mundo, atua em 83 países, operando no Brasil desde 1876. Detentora de um lucro líquido de mais de 8,9\%, equivalente a 5,24 bilhões de dólares. Para o primeiro semestre de 2012, a Nestlé ressalta ainda que suas vendas nos mercados emergentes aumentaram 12,9\% em detrimento aos países desenvolvidos, que somaram $2,6 \%$ no mesmo ano. A empresa revela, também, que $26 \%$ de suas vendas concentram-se em produtos lácteos (NESTLE'S..., 2012).

Verifica-se na Figura 6 que aproximadamente $22,45 \%$ das patentes registradas do setor alimentício no INPI relacionadas a pro, pré e simbióticos originaram-se de depositantes nacionais, designados junto ao INPI como "residentes" (pessoas que moram no Brasil). Dessa forma,

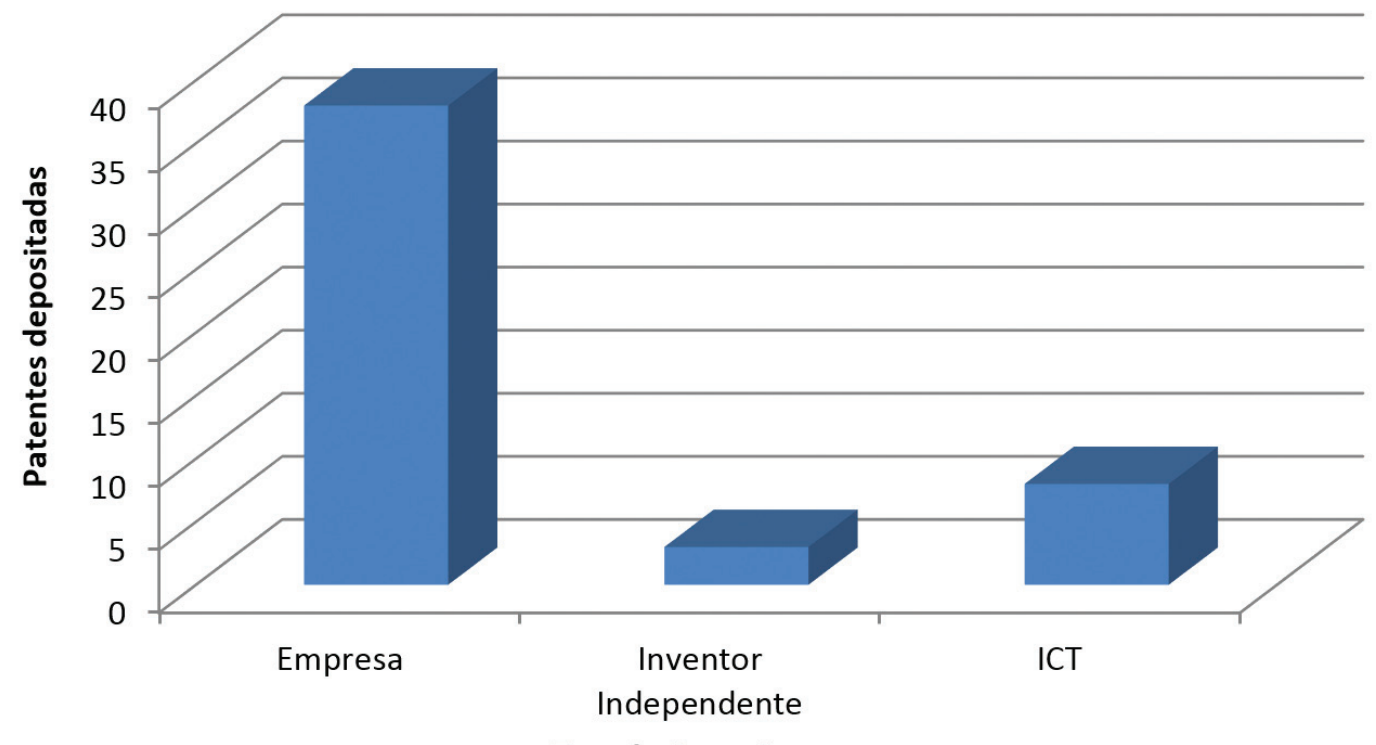

Tipo de Depositante

Figura 4. Distribuição de depósitos dos documentos de patentes no INPI relacionadas aos pró, pré, e simbióticos no setor alimentício por tipo de depositante.

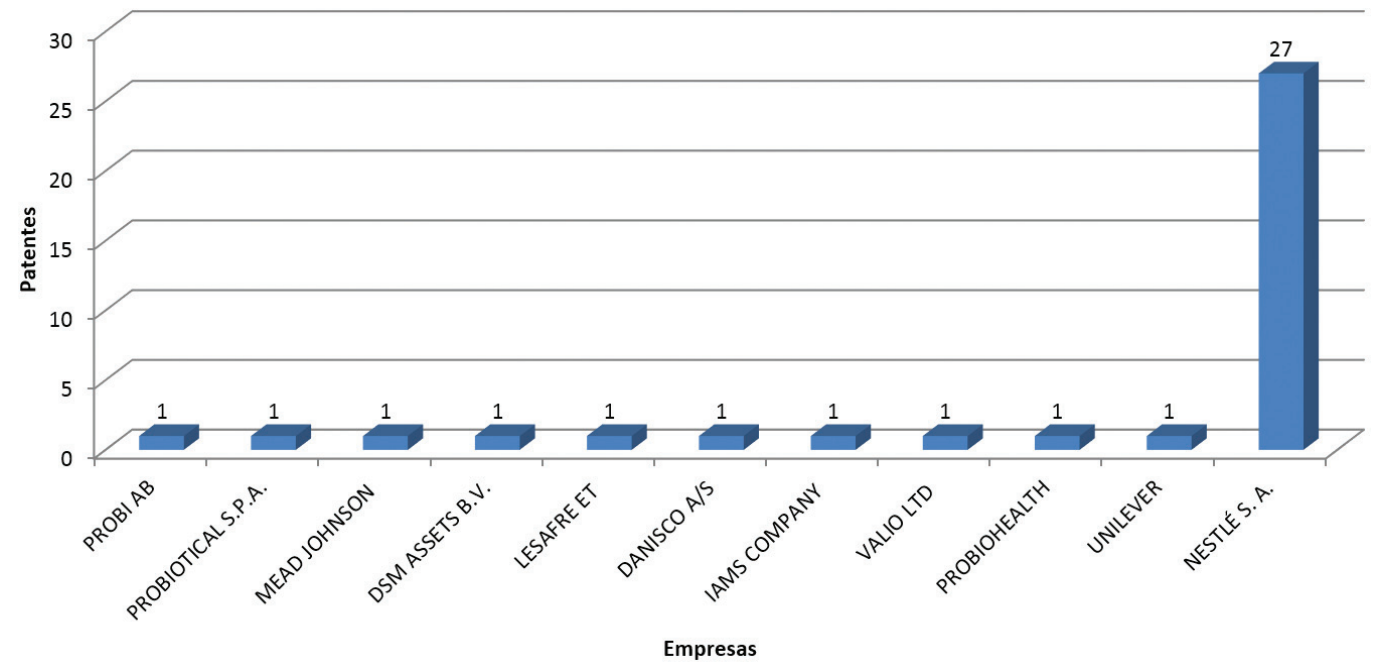

Figura 5. Distribuição de depósitos dos documentos de patentes no INPI relacionadas aos pró, pré e simbióticos no setor alimentício por empresa depositante. 
Análise das patentes de tecnologias relacionadas aos probióticos, prebióticos e simbióticos no Brasil SANTOS, F. L. et al.

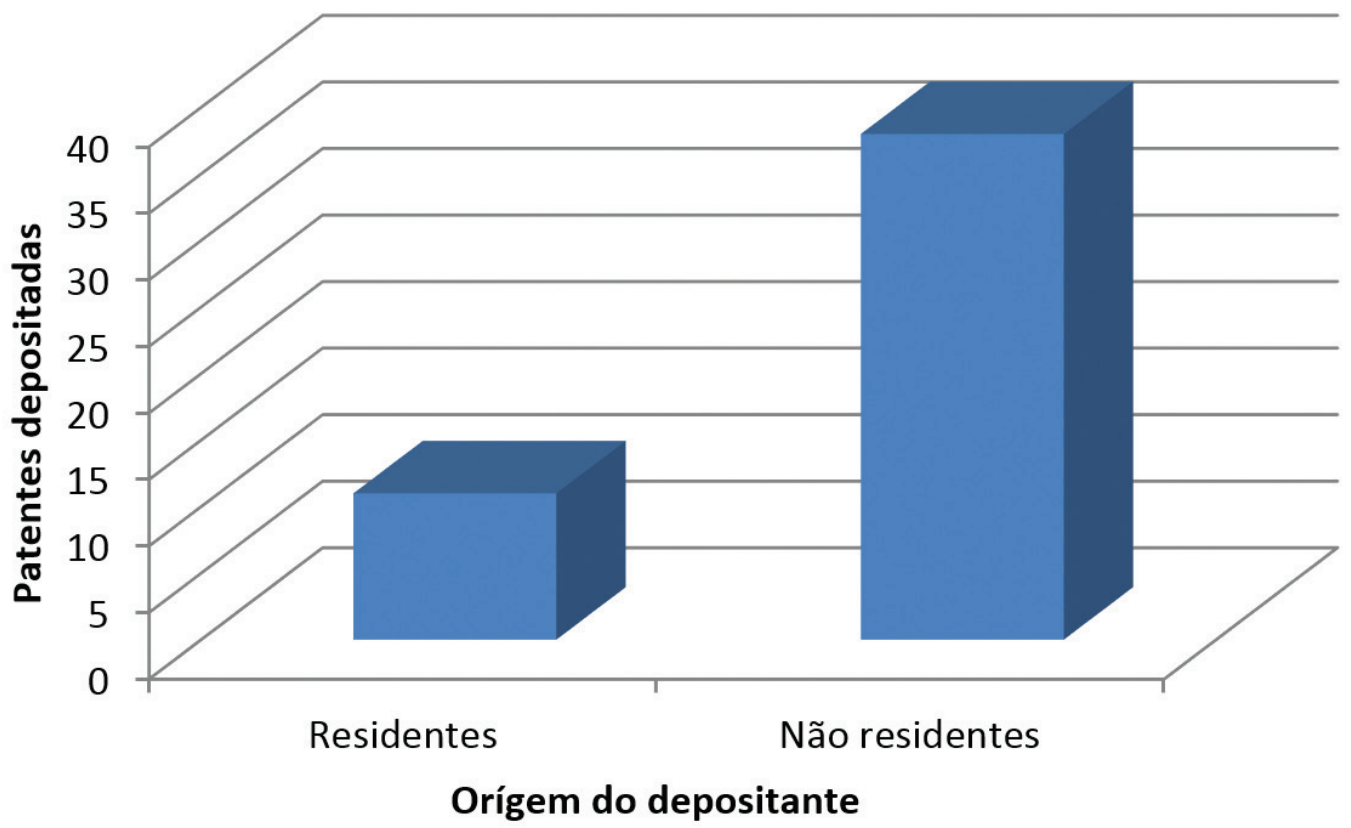

Figura 6. Quantidade de patentes depositadas no INPI referentes aos termos pró, pré e simbióticos do setor alimentício.

a maioria das invenções que solicitaram proteção no país é desenvolvida no exterior, demonstrando o interesse estrangeiro das empresas produtoras de probióticos, prebióticos e simbióticos que buscam proteção para suas invenções existentes no Brasil.

Viotti (2008) ressalta que a partir de 1990, tardiamente, o Brasil passou a incluir, de maneira explícita entre os principais objetivos da política, a promoção da inovação tecnológica, justificando o número reduzido de depósitos de patentes brasileiras. Nos últimos anos, o governo brasileiro tem estimulado a inovação nas indústrias, oferecendo diversos incentivos para empresas que investem em pesquisa e desenvolvimento (P\&D) no país. Dessa forma, a proporção de pedidos de patentes nacionais vem aumentando ao longo do tempo.

\section{Conclusões}

A busca através dos termos relacionados aos probióticos, prebióticos e simbióticos revelou que o Brasil tem um universo de 101 pedidos de patentes protocolados no INPI e que desse total apenas 22,45\% foram de residentes, implicando na necessidade de ampliar os investimentos em P\&D e proteção das propriedades industriais para geração de novos produtos.

Em 2010 ocorreu um aumento bastante promissor dos depósitos de patentes, tendo uma maior participação nos pedidos das empresas especializadas do setor.

A indústria de alimentos possui quase metade dos pedidos de proteção solicitados no INPI, revelando-se como majoritária desses pedidos a Nestlé S.A.
A quantidade de patentes depositadas ainda é incipiente em relação aos estudos e pesquisas realizados no Brasil sobre o tema, necessitando de maior incentivo governamental no sentido de criar parcerias entre as empresas e as ICT.

\section{Referências}

AGUIRRE-BASTOS, C.; GUPTA, P. M. Science, Technology and Innovation Policies in Latin America: Do They Work? Interciência, Caracas, v. 34, n. 12, p. 865-872, 2009.

AMERICAN DIETETIC ASSOCIATION - ADA. Position of the American Dietetic Association: Functional Foods. Journal of the American Dietetic Association, Bethesda, v. 109, n. 4, p. 735-746, 2009. http://dx.doi.org/10.1016/j.jada.2009.02.023

BRASIL. Lei n. 9.279, de 14 de maio de 1996. Regula Direitos e Obrigações Relativos à Propriedade Industrial. Diário Oficial da República Federativa do Brasil, Brasília, 15 maio 1996. Seção 1, p. 8353.

CARVALHO, C.; SILVA, M.; CARDOSO, P. Leite Fermentado com Kefir: Hazard Analysis Critical Control Points. Porto: Faculdade de Ciências, Universidade do Porto, 2010. p. 1-15.

CAVALCANTI, M.; GOMES, E.; PEREIRA, A. Gestão de Empresas na Sociedade do Conhecimento: Um Roteiro para a Ação. Rio de Janeiro: Campus, 2001.

EUROMONITOR INTERNATIONAL. 2013. Disponível em: <http:// www.euromonitor.com/brazil>. Acesso em: 15 ago. 2014.

FERREIRA, C. L. L. F. Grupo de Bactérias Lácticas e Aplicação Tecnológica de Bactérias Probióticas. In: FERREIRA, C. L. L. F. 
Análise das patentes de tecnologias relacionadas aos probióticos, prebióticos e simbióticos no Brasil

SANTOS, F. L. et al.

Prebióticos e Probióticos: Atualização e Prospecção. Rio de Janeiro: Rubio. 2012. p. 1-27.

FOOD AND AGRICULTURE ORGANIZATION OF THE UNITED STATES - FAO; WORLD HEALTH ORGANIZATION - WHO. Probiotics in Food: Health and Nutritional Properties and Guidelines for Evaluation. Roma, 2006. (FAO Food and Nutrition Paper, n. 85).

FOOD QUALITY AND STANDARDS SERVICE - AGNS; FOOD AND AGRICULTURE ORGANIZATION OF THE UNITED NATIONS - FAO. Technical Meeting on Prebiotics. Roma, 2007. (FAO Technical Meeting Report).

NESTLE'S Half-year Profits Rise Led by Emerging Markets. BBC NEWS Business, 09 ago. 2012. Disponível em: <http://www. bbc.co.uk/news/business-19191829>. Acesso em: 19 fev. 2013.

SAAD, S. M. I.; KOMATSU, T. R.; GRANATO, D.; BRANCO, G. F.; BURITI, F. C. A. Probióticos e Prebióticos em Alimentos: Aspectos Tecnológicos, Legislação e Segurança no Uso. In: SAAD, S. M. I.; CRUZ, A. G.; FARIA, J. A. F. Probióticos e Prebióticos em Alimentos: Fundamentos e Aplicações Tecnológicas. São Paulo: Varela, 2011. p. 23-49.

SANTOS, F. L. O Papel das ICT no Desenvolvimento Tecnológico do Brasil. In: SANTOS, F. L. (Org.). Desenvolvimento e
Perspectivas da Propriedade Intelectual no Brasil. Cruz das Almas: EDUFRB, 2014. p. 233-254.

SHINOTSUKA, C. R.; ALEXANDRE, M. R.; DAVID, C. M. N. Terapia Nutricional Enteral Associada a Pré, Pró e Simbióticos e Colonização do Trato Intestinal e Vias Aéreas Inferiores de Pacientes Ventilados Mecanicamente. Revista Brasileira de Terapia Intensiva, Rio de Janeiro, v. 20, n. 3, p. 241-248, 2008. SOUSA, R. C. P.; SANTOS, D. C.; NEVES, L. T. B. C.; CHAGAS, E. A. Tecnologia de Bioprocesso para Produção de Alimentos Funcionais. Revista Agro@mbiente On-line, Boa Vista, v. 7 , n. 3, p. 366-372, 2013. Disponível em: <http://revista.ufrr.br/ index.php/agroambiente/article/view/1240/1194>. Acesso em: 15 ago. 2014.

VIOTTI, E. B. Brasil: de Política de C\&T para Política de Inovação? Evolução e Desafios das Políticas Brasileiras de Ciência, Tecnologia e Inovação. In: BRASIL. MINISTÉRIO DA CIÊNCIA, TECNOLOGIA E INOVAÇÃO. CENTRO DE GESTÃO DE ESTUdOS ESTRATÉGICOS. Avaliação de Políticas de Ciência, Tecnologia e Inovação: Diálogo entre Experiências Internacionais e Brasileiras. Brasília: CGEE, 2008. p. 137-173. 